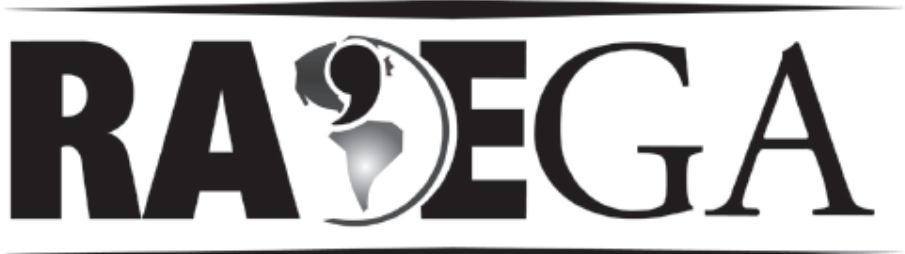

O ESPAÇO GEOGRÁFICO EM ANÁLISE

\title{
ANÁLISE ESPAÇO-TEMPORAL DOS CASOS DE INUNDAÇÕES E DE ALAGAMENTOS REGISTRADOS NA CIDADE DE CHAPECÓ-SC (1980-2010)
}

\section{SPATIO-TEMPORAL ANALYSIS OF FLOODS CASES REGISTERED IN THE CHAPECÓ CITY, SANTA CATARINA STATE (1980-2010)}

\author{
Andrey Luis Binda ${ }^{1}$ \\ Elaiz Aparecida Mensch Buffon ${ }^{2}$ \\ Maycon Fritzen ${ }^{3}$
}

\section{Resumo}

O presente trabalho tem como objetivo reconhecer espacialmente e temporalmente casos de inundações e alagamentos ocorridos na cidade de Chapecó, mesorregião oeste catarinense, no período de 1980-2010, a partir da consulta em manchetes publicadas em jornais locais impressos. Os resultados indicam que: 1) os bairros mais atingidos foram o Centro, Santa Maria, São Pedro, Passo dos Fortes e Efapi; 2) o maior número de casos por ano nem sempre estiveram relacionados a ocorrência do fenômeno El Niño; 3) a distribuição mensal dos casos apresenta correlação com os mecanismos de gênese das chuvas na região e, 4) o aumento da população urbana contribuiu para o aumento no número de casos de inundações e alagamentos.

Palavras-chave: drenagem urbana; expansão urbana; manchetes de jornais.

\footnotetext{
${ }^{1}$ Professor Assistente da Universidade Federal da Fronteira Sul - UFFS - Chapecó-SC. Doutorando em Geografia pela Universidade Federal do Rio Grande do Sul - UFRGS - Porto Alegre-RS. E-mail: abinda@uffs.edu.br

${ }^{2}$ Discente do curso de Geografia da Universidade Federal da Fronteira Sul - UFFS - Chapecó-SC. Bolsista de Iniciação Acadêmica. E-mail: elaiz2@hotmail.com

${ }^{3}$ Discente do curso de Geografia da Universidade Federal da Fronteira Sul - UFFS - Chapecó-SC. Bolsista de Iniciação Científica. E-mail: maycon ml@hotmail.com
} 


\section{Abstract}

This paper aims to recognize spatially and temporally cases of floods occurred in the Chapecó City, west region of Santa Catarina State, in the period 19802010, from the query in headlines published in printed local newspapers. The results indicate that: 1 ) the districts most affected were the Center, Santa Maria, São Pedro, Passo dos Fortes and Efapi; 2) the largest number of cases per year were not always related to the occurrence of El Niño; 3) the monthly distribution of cases is correlated with the mechanisms of rainfall genesis in the region, and 4) the increase of urban population contributed to the rise in cases of floods.

Key-words: urban drainage; urban expansion; headlines.

\section{INTRODUÇÃO}

A urbanização é considerada a maior manifestação da ação humana sobre um determinado espaço e constitui, consequentemente, em uma das maiores formas de impacto sobre uma bacia hidrográfica. As alterações no uso do solo promovem, além de mudanças hidrossedimentológicas, mudanças na frequência com que tais eventos ocorrem temporalmente (WOLMAN, 1967; BERTONI \& TUCCI, 2003). O desenvolvimento urbano, por exemplo, tende a aumentar a magnitude e a frequência com que ocorrem inundações (KONRAD \& BOOTH, 2005; CHIN, 2006; BOTELHO, 2011), visto que a cidade modifica os processos hidrológicos, proporcionando maior escoamento, devido a fatores como a diminuição da infiltração, da interceptação, do armazenamento nas depressões do terreno e ao aumento na eficiência do fluxo promovido pela impermeabilização do solo, principalmente pela pavimentação das vias (MONTGOMERY \& BUFFINGTON, 1998; KONRAD \& BOOTH, 2005; VIEIRA \& CUNHA, 2006; BOTELHO, 2011).

Segundo Henshaw \& Booth (2000), a transição de uma bacia hidrográfica florestada para urbana engloba a remoção da vegetação, a compactação dos solos, a criação de superfícies impermeáveis e alterações na rede de drenagem natural, aspectos que terão reflexos no aumento do escoamento superficial e no volume de sedimentos (VIEIRA \& CUNHA, 2006), principalmente na fase inicial de implantação (ou expansão) da cidade 
(WOLMAN, 1967). Essas alterações promovem a diminuição do tempo de concentração (lag time) devido ao fato de que a água escoada superficialmente chega muito mais rápido ao sistema de drenagem do que outrora (LEOPOLD, 1991; TUCCI, 2003; KONRAD \& BOOTH, 2005; BOTELHO, 2011), aumentando o pico de vazão, que, segundo a literatura, pode ser de duas (LEOPOLD, 1991), quatro (CHIN, 2006) ou até seis vezes (WOLMAN, 1967) maior do que no estágio anterior ao desenvolvimento urbano.

Kobiyama et al. (2006) mencionam ainda que, embora os termos enchente e inundação venham sendo utilizados como sinônimos, eles apresentam diferenças importantes. Enchente refere-se à variação do nível das águas dentro do canal e inundação consiste no processo de ocupação das planícies de inundação pelas águas (HERRMANN et al., 2005). É importante salientar que inundações são fenômenos naturais e apresentam certo intervalo de recorrência que varia de acordo com as características climáticas regionais (LEOPOLD et al., 1964; TUCCI, 2003; CUNHA, 2007). Entretanto, quando o homem ocupa a bacia hidrográfica, fixando edificações em áreas próximas aos rios e que naturalmente são susceptíveis a fluxos durante eventos de alta magnitude, as inundações tornam-se maiores, afetando áreas cada vez mais amplas do que aquelas relacionadas a eventos de mesma magnitude no estágio anterior ao desenvolvimento urbano.

Desse modo, as inundações podem ser tachadas como desastres naturais de origem hidrológica (KOBIYAMA et al., 2006) com importantes reflexos sobre a sociedade que ocupa as áreas de risco. Além disso, há ainda os casos de alagamentos que são relacionados ao acúmulo de água em áreas distantes dos canais fluviais e de grande ocorrência nas áreas urbanizadas, sobretudo, pela impermeabilização do solo e pela deficiência da drenagem de águas pluviais (SOUZA, 2004). Assim, as cidades, em virtude das intensas mudanças hidrológicas promovidas pela urbanização, são locais onde as inundações e os alagamentos trazem maiores prejuízos, tanto econômicos e sociais, como de saúde, sem contar os transtornos em relação aos fluxos de veículos e de pessoas. 
Para Silveira et al. (2009), as inundações correspondem ao principal desastre natural que ocorre no Brasil, com destaque para as do Estado de Santa Catarina, onde os casos de inundações trazem prejuízos econômicos e sociais vultosos (HERRMANN et al., 2005). É importante salientar que nos últimos anos tem ocorrido um considerável aumento nos casos de inundações bruscas no Estado de Santa Catarina, inundações decorrentes, sobretudo da urbanização (MARCELINO \& GOERL, 2005).

Nesse sentido, o presente trabalho tem como objetivo reconhecer casos de inundações e alagamentos ocorridos na cidade de Chapecó, mesorregião oeste catarinense, a partir da consulta em manchetes publicadas em jornais locais impressos. Essa pesquisa é justificada devido ao crescimento populacional acelerado verificado em Chapecó nos últimos 30 anos (19802010) e que permitiu a ocupação de novas áreas, sobretudo na bacia hidrográfica do Lajeado Passo dos Índios e seus tributários. Silveira et al. (2007) chamam a atenção para o fato de que trabalhos dessa natureza são importantes para a criação de medidas mitigadoras.

\section{MATERIAIS E MÉTODOS}

\section{Localização e Características Gerais da Área de Estudo}

O município de Chapecó está localizado na mesorregião oeste do Estado de Santa Catarina (Figura 1), na Região Sul do Brasil. Faz limites ao norte com os municípios de Coronel Freitas e Cordilheira Alta; ao sul, com o Estado do Rio Grande Sul; a leste, com Seara, Xaxim, Arvoredo, Itá e Paial; e a oeste, com Guatambu, Planalto Alegre e Nova Itaberaba. A área do município perfaz $625,4 \mathrm{~km}^{2}$, sendo que $113,2 \mathrm{~km}^{2}$ correspondem ao perímetro urbano (PREFEITURA MUNICIPAL DE CHAPECÓ, 2011). 


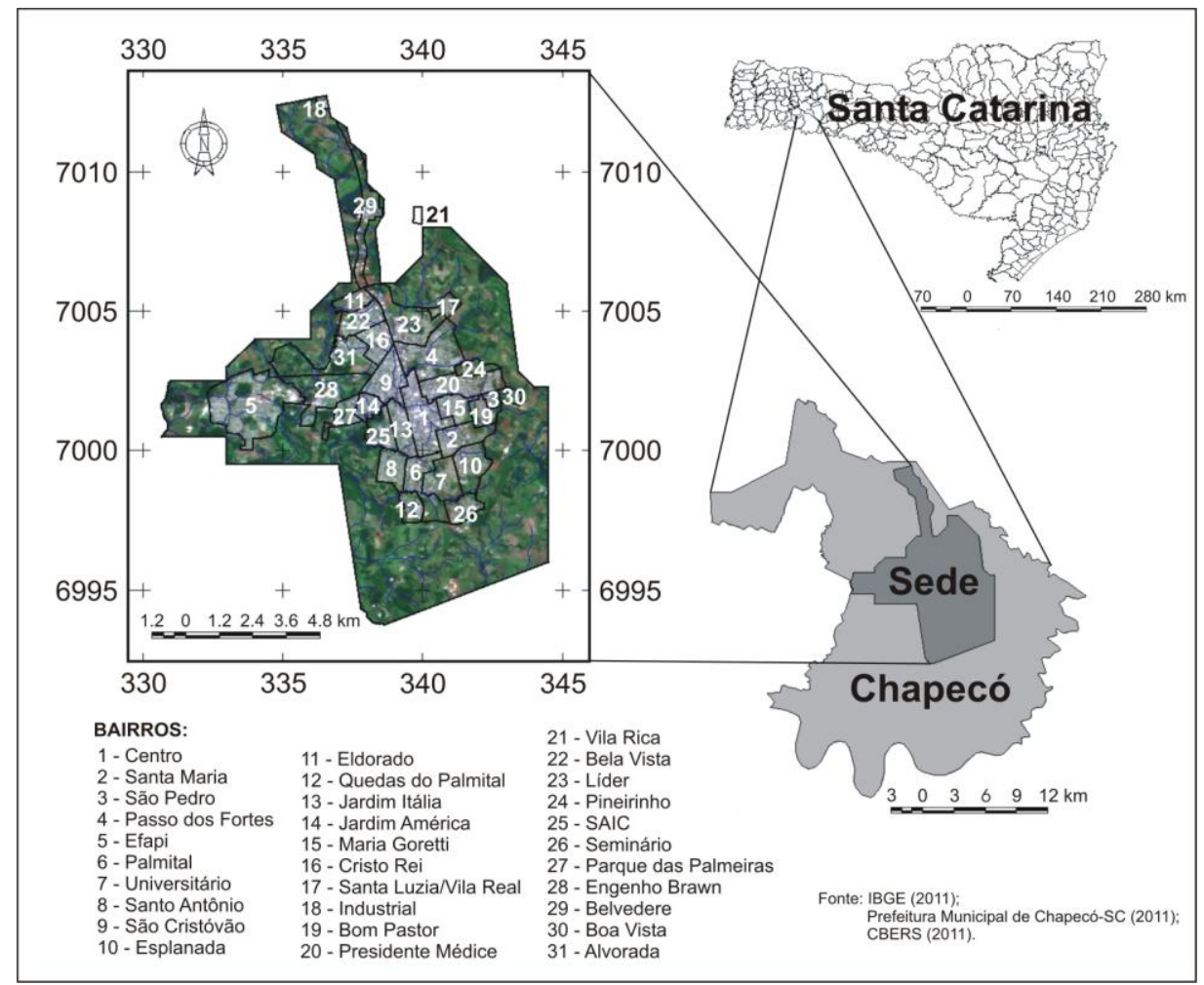

Figura 1: Localização da sede urbana de Chapecó-SC. Organização e edição: Andrey Luis Binda (2012).

A litologia predominante no município de Chapecó corresponde às rochas da Formação Serra Geral, originadas por derrames de lava de natureza básica, intermediária e ácida, representados, sobretudo, por basaltos, dacitos, riodacitos, riolitos (SCHEIBE, 1986; NARDY, 1995), sobre os quais se desenvolvem neossolos, cambissolos, argissolos ou latossolos (PREFEITURA MUNICIPAL DE CHAPECÓ, 2011). Geomorfologicamente, o município encontra-se no Planalto Catarinense, mais especificamente no Planalto Oeste da Bacia Hidrográfica do Rio Uruguai, drenado por rios com lineamentos predominantemente E-W, SW-NE e N-S (PELUSO JÚNIOR, 1986).

O clima do município de Chapecó é caracterizado como Subtropical Úmido ou Mesotérmico do Tipo Temperado, cujas principais características são temperaturas baixas e geadas no inverno, ocasionadas pela passagem de frentes frias pela região e precipitação pluviométrica distribuída regularmente ao longo do ano, embora existam desvios positivos (EI Niño) e negativos (La Niña) (NIMER, 1989; MENDONÇA \& DANNI-OLIVEIRA, 2007). A precipitação 
média anual de Chapecó é de cerca de $2.611 \mathrm{~mm}$ e a temperatura média anual é de $19,6^{\circ} \mathrm{C}$ (PREFEITURA MUNICIPAL DE CHAPECÓ, 2011).

\section{Descrição da Pesquisa}

O presente trabalho foi elaborado baseado no levantamento histórico realizado em jornais locais impressos (O Jornal Catarinense, Diário da Manhã e Diário do Iguaçu) - disponíveis na Biblioteca Pública Municipal de Chapecó-SC "Neiva Maria Andreatta Costella" e no Centro de Memória do Oeste Catarinense (CEON/Unochapecó) - no período de 1980 a 2010 e na quantificação anual, mensal e por bairros dos casos de inundações e alagamentos relatados nas manchetes.

O mapeamento espaço-temporal dos casos de inundações e alagamentos na cidade de Chapecó foi realizado utilizando o software SPRING - INPE@ Versão 5.1 .5 - Sistema de Processamento de Informações Georreferenciadas (Copyright - Instituto Nacional de Pesquisas Espaciais INPE), desenvolvido pela Divisão de Processamento de Imagens - DPI do Instituto Nacional de Pesquisas Espaciais (INPE). Os materiais cartográficos utilizados corresponderam ao banco de dados vetoriais disponibilizado pela Prefeitura Municipal de Chapecó-SC ${ }^{4}$.

\section{RESULTADOS E DISCUSSÕES}

\section{Aumento da População Urbana de Chapecó-SC (1960-2010)}

A dinâmica populacional no Brasil tem demonstrado que a partir do ano de 1940, o país até então predominantemente rural, passa a concentrar a maior parte da população nas áreas urbanas. Esse processo, desencadeado pelo êxodo rural permitiu com que em 1991, a população urbana atingisse cerca de $77,13 \%$, com estimativas que essa proporção esteja atualmente alcançando valores superiores a 80\% (SANTOS, 1994).

Segundo informações da Prefeitura Municipal de Chapecó (2011), o crescimento populacional registrado pelo município permitiu que a população,

\footnotetext{
${ }^{4}$ Disponível em: <http://www.chapeco.sc.gov.br/secretarias/secretaria-de-planejamento/downloads.html>. Acesso em: 12 dez. 2011
} 
predominantemente rural nas décadas de 1960 e 1970 (68\% e 59\%, respectivamente) passasse a ser urbana a partir da década de 1980, quando $66 \%$ dos 55.269 habitantes se encontravam na cidade. A partir de 1980 esses valores aumentaram consideravelmente, de modo que, no último censo (2010), a população urbana atingiu cerca de $92 \%$ do total de 183.561 habitantes no município (Figura 2).

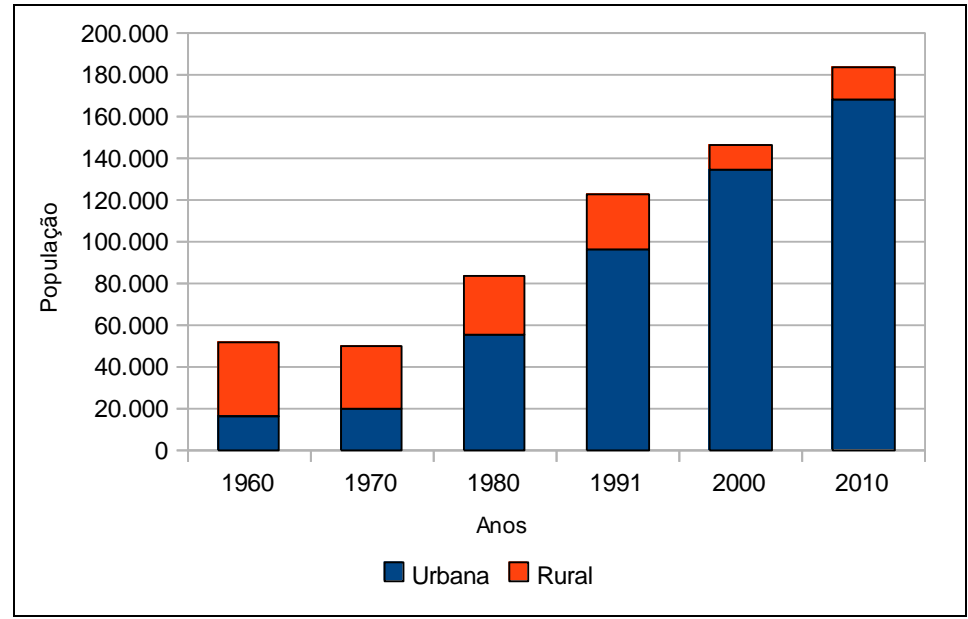

Figura 2: Crescimento populacional e local de concentração no município de Chapecó. Fonte: IBGE apud Prefeitura Municipal de Chapecó-SC (2011).

Organização: Andrey Luis Binda (2012).

\section{Inundações e Alagamentos na Cidade de Chapecó-SC (1980-2010)}

A partir das notícias sobre inundações e alagamentos publicados nos jornais consultados foi possível verificar a evolução dos casos ao longo do período de 1980-2010. Digno de nota é o fato de que foram utilizadas aqui apenas as notícias publicadas, o que, possivelmente, deve ter subestimado o valor real dos casos ocorridos na cidade. Entretanto, como será visto, essa metodologia trouxe informações pertinentes para a pesquisa, visto que aqui os casos foram agrupados por bairros.

Ao longo do período 1980-2010 foram mencionados casos que perfizeram um total de 238 ocorrências, distribuídos em praticamente todos os bairros da cidade. Na Figura 3 pode ser visualizada a distribuição anual dos casos registrados, com um aumento expressivo do número a partir de 1990, sendo que esse ano foi caracterizado como o de maior número de ocorrências, atingindo 42 casos. No período que antecede 1990, somente o ano de 1983 
apresentou um elevado valor, atingindo 16 casos. É importante salientar que, ao longo da série, 4 anos tiveram número de casos superior ao de 1983, com destaque para o já citado ano de 1990, acrescentando ainda 2000 (19 casos), 2001 (18 casos) e 2009 (19 casos).

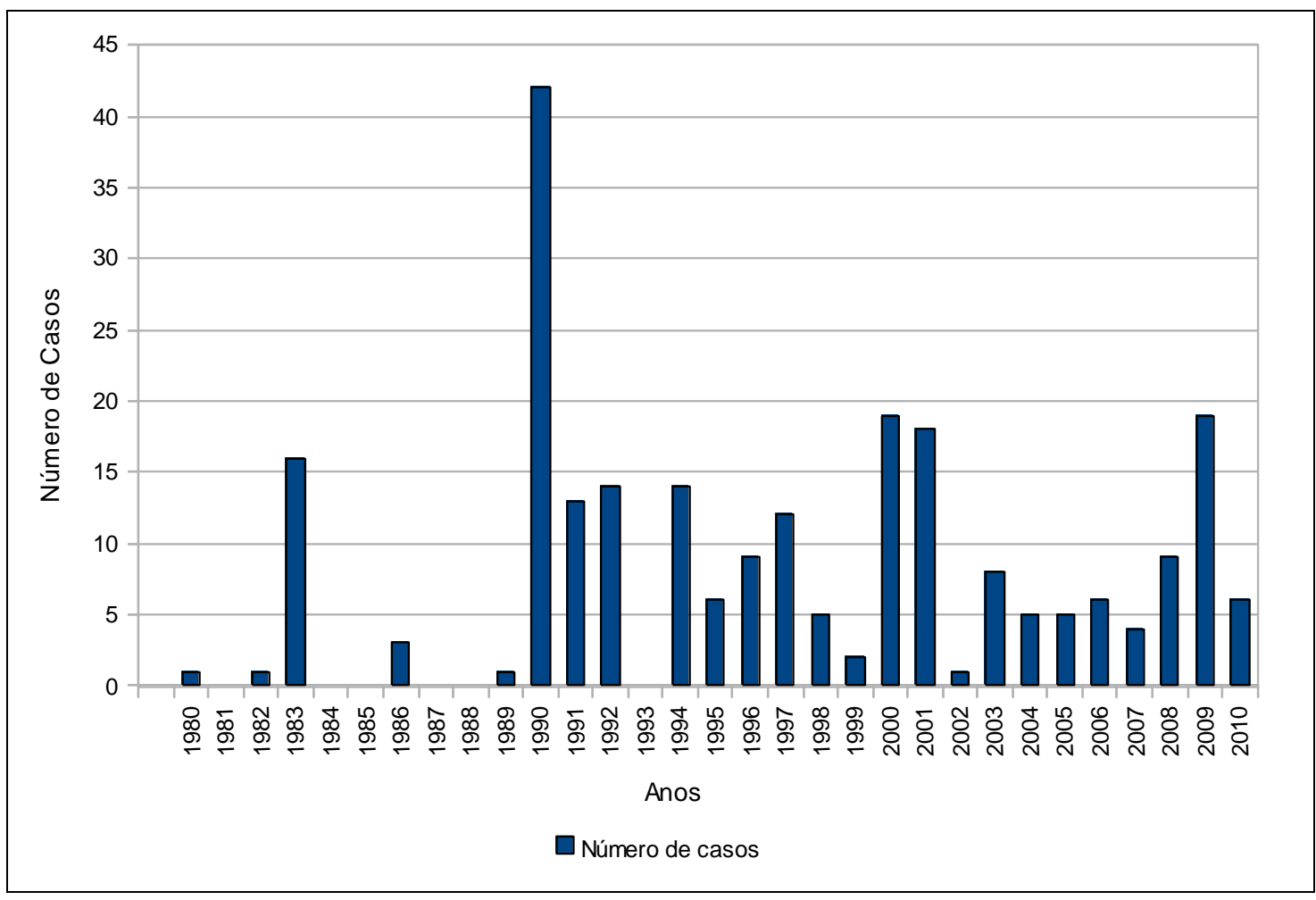

Figura 3: Número de casos de inundações e alagamentos registrados em Chapecó. Fonte: O Jornal Catarinense (1980); Diário da Manhã (1981-2000); Diário do Iguaçu (1999-2010).

Organização: Andrey Luis Binda (2012).

Ao se verificar o total de casos de inundações e alagamentos com os fenômenos controladores, percebe-se que alguns dos anos que registraram o maior número de casos estão de certo modo relacionados à ocorrência do fenômeno El Niño, tais como os anos de 1983, 1990, 1991, 1992, 1994, 1997 e 2009, todos com totais de ocorrências superiores a 10 casos no ano. Entretanto, 2000 e 2001 apresentaram um elevado total de casos, porém ocorreram num período caracterizado pela predominância do La Niña, o que demonstra que outros fatores devem adquirir importância na gênese de inundações e de alagamentos. Frente a isso, possivelmente os fatores 
preponderantes devem ter sido: 1) a ocorrência de precipitações com alta intensidade; 2) o aumento das superfícies impermeabilizadas pela expansão urbana decorrente do crescimento populacional verificado na cidade; e 3) a deficiência das obras de drenagem pluviais e galerias entupidas. Esses fatores promoviam a redução do tempo de concentração e, consequentemente, a chegada de um volume de água elevado aos canais fluviais, que, na maioria das vezes, se encontravam assoreados, sobretudo por lixo, ocasionando a inundação das áreas marginais, bem como, o alagamento de vias, de residências e de casas comerciais.

A análise mensal dos casos de inundações e alagamentos permitiu verificar que as ocorrências estão distribuídas ao longo de todo o ano (Figura 4). Entretanto, os meses caracterizados com maior número de casos no período de 1980-2010 foram: setembro (37 casos), outubro (31 casos), maio (30 casos), junho (27 casos) e fevereiro (25 casos), enquanto os meses de abril (4 casos), agosto (8 casos) e dezembro (12 casos) foram os que registraram os menores números de casos.

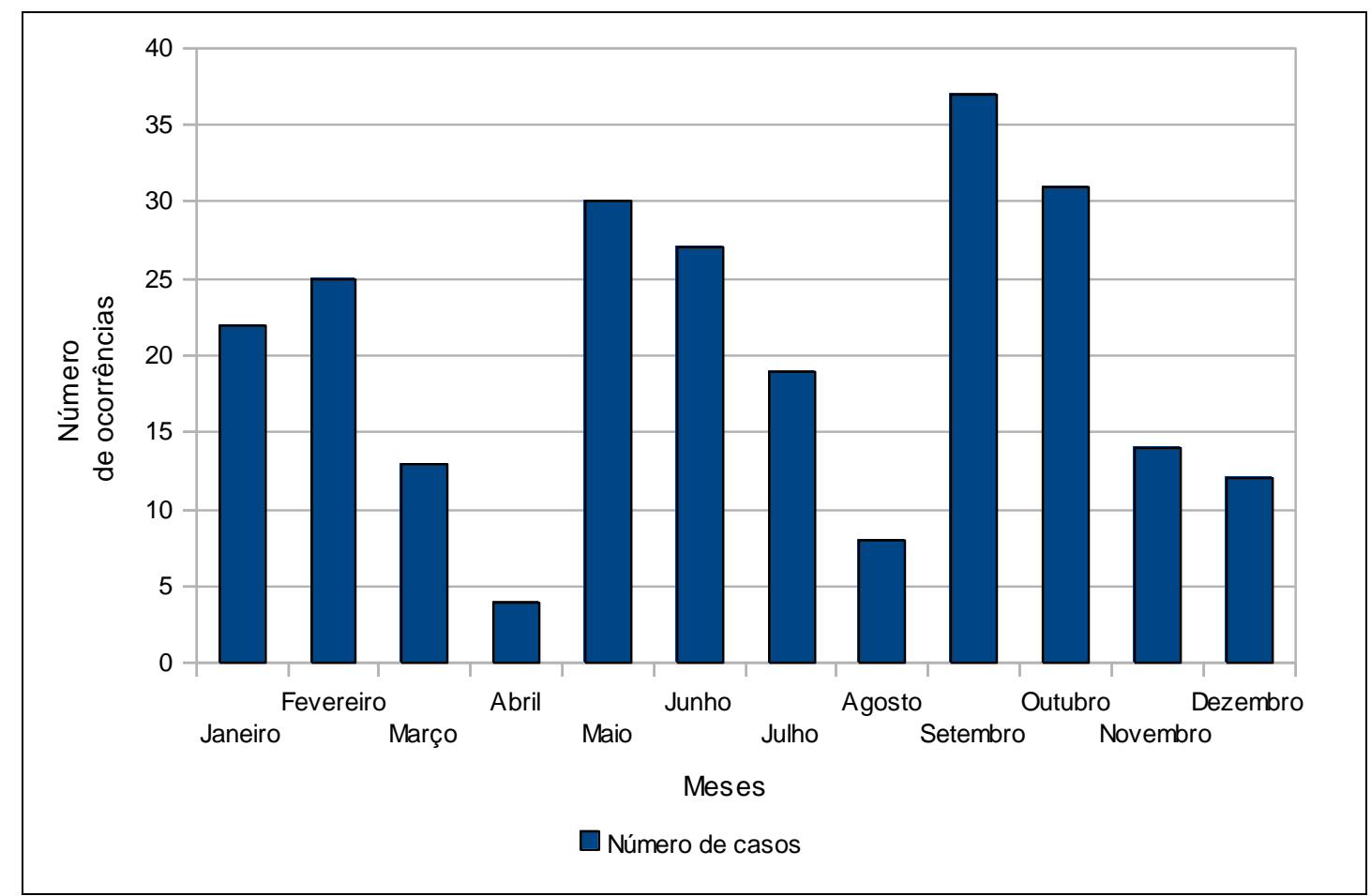

Figura 4: Número de casos mensais de inundações e alagamentos em Chapecó-SC. Fonte: O Jornal Catarinense (1980); Diário da Manhã (1981-2000); Diário do Iguaçu (1999-2010).

Organização: Andrey Luis Binda (2012). 
Mesmo assim, porém, analisando melhor a Figura 4, é possível perceber que os casos se distribuem de uma maneira peculiar, com picos nos meses de fevereiro, maio e setembro, que se reduzem até atingirem valores mínimos nos meses de abril, agosto e dezembro. Esse fato pode ser explicado, baseando-se nos mecanismos que operam na gênese da precipitação ao longo do ano. Nos meses de janeiro a março, o aquecimento diurno da superfície terrestre, vinculado à presença de umidade, promove a ocorrência de chuvas convectivas (chuvas de verão), as quais são caracterizadas por intensidade elevada e curta duração. Entre maio e junho, período em que ocorre a transição entre o outono e o inverno, o encontro das massas de ar polar com o ar quente sobre o continente origina chuvas frontais, as quais podem atingir elevados totais pluviométricos. Entre os meses de setembro e outubro, a gênese de Complexos Convectivos de Mesoescala (CCMs) no Paraguai e norte da Argentina permite o deslocamento para leste dessas áreas de instabilidade que acabam atingindo o oeste catarinense, sobretudo no fim de tarde e início da noite, promovendo chuvas intensas e fenômenos climáticos extremos.

Com relação à espacialização dos casos de inundações e alagamentos na cidade de Chapecó (Figura 5), deve-se levar em consideração que, ao longo do período compreendido entre 1980 e 2010, vários bairros foram criados a partir do desmembramento de bairros mais antigos, fato que pode "mascarar" parcialmente a distribuição dos casos de inundações e alagamentos. Outra questão que deve ser esclarecida é que aqui foi contabilizado apenas o total de casos por bairro, não refletindo a intensidade e a magnitude dos eventos. Dessa forma, os resultados aqui apresentados devem ser tomados como indícios importantes, para se reconhecer bairros onde as inundações e alagamentos são problemas crônicos.

Feita essa breve descrição preventiva, é possível perceber que, no período entre 1980-2010, os bairros com ocupação mais antiga, tais como o Centro (35 casos), Santa Maria (23 casos), São Pedro (19 casos), Passo dos Fortes (17 casos) e Efapi (16 casos) foram os que mais registraram casos de inundações e alagamentos, enquanto os bairros SAIC, Seminário, Parque das 
Palmeiras, Engenho Brawn e Belvedere, alguns dos quais criados sobretudo na década de 1990, foram os locais onde menos ocorreram, totalizando apenas 1 caso (Tabela 1). Os bairros Boa Vista e Alvorada não foram citados em nenhuma manchete e, por isso, foram deixados como sem ocorrência.

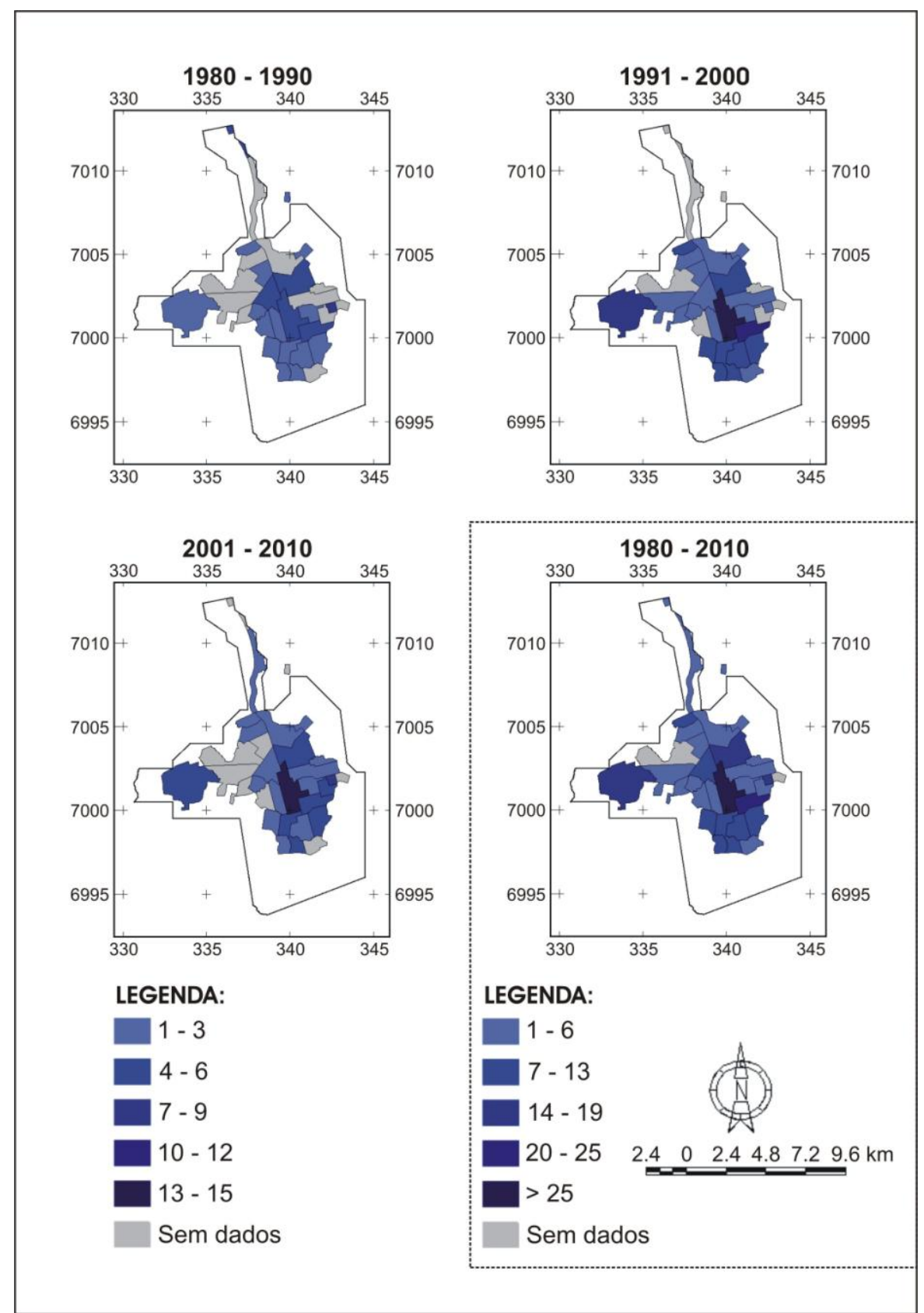

Figura 5: Espacialização dos casos de inundações e alagamentos no período entre 1980-2010.

Fonte: O Jornal Catarinense (1980); Diário da Manhã (1981-2000); Diário do Iguaçu (1999-2010).

Organização e edição: Andrey Luis Binda (2012). 
Observando, porém, a Figura 5 e a Tabela 1, pode-se perceber que a distribuição dos casos de inundações e alagamentos na cidade de Chapecó não ocorreu de maneira uniforme ao longo do período entre 1980-2010. Analisando mais de perto essas informações, fica nítido que, entre 1980-1990, os registros (63 casos) se encontram distribuídos homogeneamente em vários bairros da cidade, sendo os locais com maior ocorrência os bairros mais centrais e de ocupação mais antiga de Chapecó, tais como o Centro, São Cristóvão e Santa Maria (6 casos cada), com destaque para o bairro São Pedro (8 casos).

Tabela 1: Número de casos de alagamentos por bairros no período entre 1980-2010.

\begin{tabular}{|c|c|c|c|c|}
\hline BAIRRO & $1980-1990$ & $1991-2000$ & $2001-2010$ & TOTAL \\
\hline Centro & 6 & 15 & 14 & 35 \\
\hline Santa Maria & 6 & 11 & 6 & 23 \\
\hline São Pedro & 8 & 3 & 8 & 19 \\
\hline Passo dos Fortes & 5 & 6 & 6 & 17 \\
\hline Efapi & 2 & 9 & 5 & 16 \\
\hline Palmital & 3 & 5 & 4 & 12 \\
\hline Universitário & 3 & 6 & 3 & 12 \\
\hline Santo Antônio & 3 & 6 & 2 & 11 \\
\hline São Cristóvão & 6 & 2 & 3 & 11 \\
\hline Esplanada & 1 & 6 & 4 & 11 \\
\hline Eldorado & 2 & 6 & 2 & 10 \\
\hline Quedas do Palmital & 2 & 4 & 2 & 8 \\
\hline Jardim Itália & 3 & 1 & 3 & 7 \\
\hline Jardim América & 3 & 1 & 2 & 6 \\
\hline Maria Goretti & 1 & 2 & 3 & 6 \\
\hline Cristo Rei & 0 & 3 & 2 & 5 \\
\hline Santa Luzia/Vila Real & 1 & 2 & 2 & 5 \\
\hline Industrial & 4 & 0 & 0 & 4 \\
\hline Bom Pastor & 0 & 0 & 4 & 4 \\
\hline Presidente Médice & 0 & 1 & 2 & 3 \\
\hline Vila Rica & 2 & 0 & 0 & 2 \\
\hline Bela Vista & 1 & 1 & 0 & 2 \\
\hline Líder & 0 & 1 & 1 & 2 \\
\hline Pinheirinho & 0 & 0 & 2 & 2 \\
\hline SAIC & 1 & 0 & 0 & 1 \\
\hline Seminário & 0 & 1 & 0 & 1 \\
\hline Parque das Palmeiras & 0 & 1 & 0 & 1 \\
\hline Engenho Brawn & 0 & 1 & 0 & 1 \\
\hline Belvedere & 0 & 0 & 1 & 1 \\
\hline TOTAL & 63 & 94 & 81 & 238 \\
\hline
\end{tabular}

Fonte: O Jornal Catarinense (1980); Diário da Manhã (1981-2000); Diário do Iguaçu (1999-2010).

Organização: Andrey Luis Binda (2012). 
Se, no período entre 1980-1990, a distribuição dos registros ocorria de forma homogênea, entre 1991-2000 pode-se visualizar que não apenas o número total de casos aumentou (94 casos), mas também ocorreram heterogeneamente na cidade, ou seja, embora vários bairros tivessem ao longo desse período registros de inundações e alagamentos, alguns começaram a apresentar pontos crônicos, em vista do elevado número de ocorrências. Nessa ocasião, os bairros Centro (15 casos) e Santa Maria (11 casos) foram os que obtiveram o maior número de casos, junto com os bairros Efapi (9 casos), Passo dos Fortes, Universitário, Santo Antônio, Esplanada e Eldorado ( 6 casos cada), sendo que a causa principal para essas ocorrências foi, possivelmente $o$ estrangulamento de canais fluviais e a deficiência da drenagem pluvial.

O período entre 1991-2010 tem características semelhantes à década anterior, ou seja, a heterogeneidade na espacialização e a existência de bairros com pontos crônicos de inundações e alagamentos. O bairro Centro (14 casos) continua sendo o local com o maior número de casos, seguido pelos bairros São Pedro (8 casos), Santa Maria e Passo dos Fortes (6 casos cada). A redução considerável do número de registros em alguns bairros nesse período deve ser decorrente das constantes obras realizadas pela Prefeitura Municipal de Chapecó, tais como a melhoria na drenagem pluvial e na limpeza dos rios urbanos.

\section{CONSIDERAÇÕES FINAIS}

Casos de inundações e de alagamentos na cidade de Chapecó têm ocorrido desde a década de 1980, porém eles se têm tornado cada vez mais frequentes, principalmente, a partir de 1990, o que demonstra que o aumento da população, a expansão e a infraestrutura urbana assumem papel fundamental nessas ocorrências. Em Chapecó, conforme foi visto, o aumento populacional a partir da década de 1980 promoveu um incremento de pessoas na cidade que culminou, em 2010, num total de aproximadamente 183 mil habitantes, dos quais $92 \%$ residem a área urbana. Esse fato pode ser correlacionado com a afirmação de Botelho (2011) na qual inundações têm aumentado em número e em frequência nas áreas urbanas do Brasil, e com 
Marcelino e Goerl (2005), que enfatizam que, no Estado de Santa Catarina, inundações bruscas têm causado danos e prejuízos, principalmente com o aumento da urbanização a partir da década de 1990.

A mitigação dos constantes casos de inundações e alagamentos em Chapecó deve passar primeiramente pelo planejamento em longo prazo do sistema de drenagem, buscando antecipar os retrospectos da ocupação urbana sobre as bacias hidrográficas. Ademais, deve-se refletir sobre modelos de ocupação diferenciada, concebendo a utilização de novos materiais e técnicas, sem se esquecer da importância das leis de uso do solo (BOTELHO, 2011), devendo restringir a ocupação de áreas de risco (HERMANN, 2005). Para finalizar, é de suma importância o exposto por Botelho (2011, p. 93), quando diz que "[...] a ideia de 'desconstruir' cidades é inconcebível e ilusória, pois não podemos deixar de construir moradias, asfaltar ruas, erguer centros empresariais, etc. [...]", sendo necessário, portanto, refletir que o sítio urbano se encontra assentado sobre bacias hidrográficas nas quais as alterações promovidas pelo desenvolvimento da cidade proporcionam alterações no sistema hidrológico-hidrográfico, com importantes reflexos sobre a sociedade.

\section{REFERÊNCIAS}

BERTONI, J. C. \& TUCCI, C. E. M. Urbanización. In: TUCCI, C. E. M. \& BERTONI, C. (Orgs.). Inundações urbanas na América do Sul. Porto Alegre, RS: Associação Brasileira de Recursos Hídricos, 2003.

BOTELHO, R. G. M. Bacias hidrográficas urbanas. In: GUERRA, A. J. T. (Org). Geomorfologia urbana. Rio de Janeiro: Bertrand Brasil, 2011. p. 71-115.

CHIN, A. Urban transformation of river landscape in a global context. Geomorphology, v. 79, 2006, p. 460-487.

CUNHA, S. B. Canais fluviais e a questão ambiental. In: CUNHA, S. B. \& GUERRA, A. J. T. (Orgs.). A questão ambiental: diferentes abordagens. 3. ed. Rio de Janeiro: Bertrand Brasil, 2007. p.219-238.

HENSHAW, P.C. \& BOOTH, D. B. Natural restabilization of stream channels in urban watersheds. Journal of the American Water Resources Association, v. 36, n. 6,2000 , p.1219-1236. 
HERRMANN, M. L. P. As principais conseqüências negativas provocadas pelas adversidades atmosféricas no Estado de Santa Catarina. HERRMANN (Org.). Atlas de desastres naturais do Estado de Santa Catarina. Florianópolis: IOESC, 2005. p. 67-88.

HERRMANN, M. L. P.; KOBIYAMA, M.; MARCELINO, E. V. Inundação gradual. In: HERRMANN (Org.). Atlas de desastres naturais do Estado de Santa Catarina. Florianópolis, SC: IOESC, 2005. p. 89-92.

KOBIYAMA, M. et al. Prevenção de desastres naturais: conceitos básicos. Curitiba, PR: Ed. Organic Trading, 2006. 109 p.

KONRAD, C. P. \& BOOTH, D. B. Hydrologic changes in urban streams and their ecological significance. American Fisheries Society Symposium, v. 47, 2005, p.157-177.

LEOPOLD, L. B. Lag times for small drainage basins. Catena, v. 18, 1991, p.157-171.

LEOPOLD, L. B.; WOLMAN, M. G.; MILLER, J. P. Fluvial processes in geomorphology. San Francisco: Freeman and Co., 1964. 522 p.

MARCELINO, E.V. \& GOERL, R. F. Inundação brusca. In: HERRMANN (Org.). Atlas de desastres naturais do Estado de Santa Catarina. Florianópolis, SC: IOESC, 2005. p. 93-96.

MENDONÇA, F.A. \& DANNI-OLIVEIRA, I.M. Climatologia: noções básicas e climas do Brasil. São Paulo: Oficina de Textos, 2007.

MONTGOMERY, D. R. \& BUFFINGTON, J. M. Channel processes, classification, and response. In: NAIMAN, R. \& BILBY, R. (Editors) River ecology and management. Springer-Verlang New York, Inc, 1998, p.13-42.

NARDY, A.J.R. Geologia e petrologia do vulcanismo mesozóico da Região Central da Bacia do Paraná. Tese de Doutorado. Rio Claro: IGCE-UNESP, 1995.

NIMER, E. Climatologia do Brasil. 2.ed. Rio de Janeiro: IBGE, Depto de Recursos Naturais e Estudos Ambientais, 1989.

PELUSO JÚNIOR, V.A. O relevo do território Catarinense. Geosul, n.2, 1986. p.7-69.

PREFEITURA MUNICIPAL DE CHAPECÓ. Chapecó em dados (Agosto 2011). Disponível em: < http://www.chapeco.sc.gov.br/chapeco/chapecodados.html>. Acesso em: 15 de dezembro de 2011.

SANTOS, M. A urbanização brasileira.2.ed. São Paulo: HUCITEC, 1994. 
SCHEIBE, L.F. A Geologia de Santa Catarina: Sinopse provisória. Geosul, n.1, 1986, p.7-38.

SILVEIRA, W. N.; KOBIYAMA, M.; GOERL, R. F.; BRANDENBURG, B. História das inundações em Joinville (1851-2008). Curitiba, PR: Organic Trading, 2009. $153 \mathrm{p}$.

SOUZA, C. R. G. Risco a inundação, enchentes e alagamentos em regiões costeiras. Simpósio Brasileiro de Desastres Naturais. Florianópolis: GEDN/UFSC, 2004. p. 231-247.

TUCCI, C. E. M. Inundações e drenagem urbana. In: TUCCI, C. E. M. \& BERTONI, C. (Orgs.). Inundações urbanas na América do Sul. Porto Alegre, RS: Associação Brasileira de Recursos Hídricos, 2003.

VIEIRA, V. T. \& CUNHA, S. B. Mudanças na rede de drenagem urbana de Teresópolis-RJ. In: GUERRA, A. J. T. \& CUNHA, S. B. (Orgs.). Impactos ambientais urbanos no Brasil. 4. ed. Rio de Janeiro: Bertrand Brasil, 2006. p.111-145.

WOLMAN, M. G. A cycle of sedimentation and erosion in urban river channels. Geog. Annaler, v. 49A, 1967, p. 385-395.

\section{FONTES PRIMÁRIAS:}

O JORNAL CATARINENSE. O Jornal Catarinense, Chapecó-SC, edições de 1980. Acervo do Centro de Memória do Oeste Catarinense (CEON/Unochapecó).

DIÁRIO DA MANHÃ. Diário da Manhã, Chapecó-SC, edições de 1981 a 2000. Acervo da Biblioteca Pública Municipal Chapecó-SC "Neiva Maria Andreatta Costella".

DIÁRIO DO IGUAÇU. Diário do Iguaçu, Chapecó-SC, edições de 1999 a 2010. Acervo da Biblioteca Pública Municipal Chapecó-SC "Neiva Maria Andreatta Costella". 